\title{
A MEDICALIZAÇÃO COMO ESTRATÉGIA BIOPOLÍTICA: UM ESTUDO SOBRE O CONSUMO DE PSICOFÁRMACOS NO CONTEXTO DE UM PEQUENO MUNICÍPIO DO RIO GRANDE DO SUL
}

\author{
Vivian Tatiana Galvão Ignácio \\ Henrique Caetano Nardi \\ Universidade Federal do Rio Grande do Sul, Porto Alegre, Brasil
}

\begin{abstract}
RESUMO: Este estudo teve como objetivo compreender como o consumo de psicofármacos se legitimou como uma tecnologia de si no interior do dispositivo de medicalização. Concluímos que esta é uma tecnologia que incide sobre os corpos por estar acoplada aos modos de subjetivação contemporâneos. A análise aqui apresentada trata do contexto social de Boa Vista das Missões, um pequeno município do Rio Grande do Sul. Realizamos uma pesquisa de campo com seis meses de duração e entrevistamos uma amostra de 400 pessoas. A análise dos relatos e das informações construídas buscou dar visibilidade aos enunciados presentes nas formações discursivas e que definem e explicam o consumo de psicofármacos por $53 \%$ da população da cidade. Utilizamos a perspectiva genealógica de Michel Foucault para refletir sobre este campo de pesquisa e problematizar a produção de modos de vida marcados por formas de controle individualizantes e totalizantes ao mesmo tempo. Neste sentido, partimos do histórico da inserção dos psicofármacos em nossa cultura para entender as dimensões que ocupam neste contexto. A análise identificou as redes enunciativas no interior do dispositivo de medicalização que fundamentam uma apresentação do biopoder que se sustenta no tripé "dependência, assistencialismo, individualismo".
\end{abstract}

PALAVRAS-CHAVE: Medicalização; psicofármacos; tecnologias de si, subjetividade.

MEDICALIZATION AS A BIOPOLITICAL STRATEGY: A STUDY ABOUT THE CONSUMING OF PSYCHOACTIVE PRESCRIBED DRUGS IN A SMALL TOWN IN STATE OF RIO GRANDE DO SUL

ABSTRACT: The goal of this research was to comprehend how the consumption of psychoactive prescribed drugs was legitimated as a technology of the self inside the medicalization device (dispositf). We concluded that this is a technology that incurs on the body because it's attached to contemporary modes of subjectification. The analysis presented here refers to Boa Vista das Missões, a small town in the state of Rio Grande do Sul. We conducted a six months field research and interviewed a sample of 400 inhabitants. The speech and data analysis intended to give visibility to the statements present in the discursive formations and which define and explain the consumption of prescribed psychoactive drugs by 53\% of the local population. We used Michel Foucault's genealogical perspective to guide our understanding of the data and to query the production of lifestyles characterized by individualized and totalized forms of control. As a starting point we described the history of the introduction of psychoactive drugs in our culture in order to understand the dimension of the consumption in this specific context. The analysis identified the statements thread in the interior of the medicalization device (dispositif) that sustains a form of biopower based on the tripod of "dependence - welfarism - individualism".

KEYWORDS: Medicalization; psychoactive drugs; technologies of the self; subjectivity.

O presente artigo resulta da pesquisa de campo conduzida entre 2005-2006 cujo objetivo foi compreender como o consumo de psicofármacos se legitimou como uma tecnologia de si forjada pelo dispositivo de medicalização no contexto de Boa Vista das Missões no interior do Rio Grande do Sul (RS).

A abordagem metodológica compreendeu uma série de abordagens desde a apreensão de traços, memórias, inscrições históricas e descontínuas (próprias de uma investigação genealógica ${ }^{1}$ ) até ferramentas típicas de investigação como a entrevista quantitativo-qualitativa com 400 moradores do município de Boa Vista das Missões. Com este estudo buscamos contribuir para a construção de conhecimento acerca das políticas de saúde relacionadas ao dispositivo da medicalização (especificamente no que se refere ao consumo de psicofármacos), considerando que esta situação corresponde à produção de modos de vida no contemporâneo e à necessidade de modelos de ação que reflitam sobre os processos de subjetivação.

O dispositivo, conceito central deste estudo é, segundo Foucault (1977), um operador do poder, uma estratégia e uma forma de assujeitamento. Pode tratar-se tanto de discurso quanto práticas, de instituições quanto de táticas moventes. Aqui tratamos do dispositivo de medicalização, buscando entender como ele opera mobilizando estratégias e formas de assujeitamento, e por estar ligado à configurações de saber que dele nascem e igualmente o condicionam. É entendido como produtor de tecnologias de 
$\mathrm{si}^{2}$ que operam nos corpos como estratégias de controle legitimadas político e socialmente por estarem acopladas aos modos de subjetivação contemporâneos.

Assim, compreender os efeitos agenciadores do dispositivo da medicalização nos modos de subjetivação contemporâneos implica em entender como se atualizam as estratégias que definem a expressão da biopolítica (enquanto governo da vida) como controle da população e como uma forma de disciplinarização dos corpos. $\mathrm{O}$ dispositivo da medicalização é interior à biopolítica e, como buscaremos demonstrar em nossa análise, ele age conformando modos de ser e instaurando uma normalidade medicalizada, na qual a expressão do sofrimento (de qualquer origem e forma) não se torna objeto de reflexão e busca de construção de outras formas de ser, mas sim de um "bloqueio químico" das emoções. Entretando, o dispositivo só é potente no contexto analisado quando acoplado à uma forma específica de apresentação da biopolítica que articula formas tradicionais de gestão baseadas no assitencialismo, no paternalismo e na dependência (próprias do contexto local) com a produção de fármacos (produto do capitalismo global).

\section{Sujeitos e Campo}

O campo empírico do presente estudo é o município de Boa Vista das Missões, situado a noroeste do Rio Grande do Sul, na região do Alto Uruguai, localizado à $390 \mathrm{~km}$ da capital gaúcha. A população é de 2.209 habitantes (1.159 da zona rural e 950 da zona urbana) e a área total corresponde à $195 \mathrm{~km}^{2}{ }^{3}$ A economia do município é substancialmente agrícola (70\%), ou seja, cultivo de soja, trigo, aveia e girassol, sendo que os investimentos da indústria e comércio (30\%) estão voltados essencialmente para o setor primário. ${ }^{4}$ A emancipação política do município ${ }^{5}$ é recente: 1992. A disposição urbana, das residências é esparsa, mesmo no centro urbano, onde se encontram as áreas comercial e administrativa, e são comumente cercadas por plantações de cereais - o que tornou nosso recorte literalmente um campo.

A escolha em pesquisar este tema neste campo partiu de uma experiência de trabalho realizada em 2004, quando se verificou numa pesquisa informal a alta prevalência de consumidores de psicofármacos neste município (dos 734 sujeitos que participaram desta primeira pesquisa, 521 declararam consumir ou ter consumido psicofármacos). No levantamento do estudo atual (400 sujeitos) obtivemos o resultado de 212 consumidores ativos e/ou recentes de psicofármacos. $^{6}$

\section{Metodologia}

Para definirmos as características do campo verificamos registros, memórias, documentos e nos utilizamos de entrevistas contendo 18 questões objetivas (para estabelecermos correspondência e cruzamentos entre categorias consumo e gênero, escolaridade, ocupação, renda, tempo de uso, etc.) e 06 questões de livre expressão que compuseram as narrativas. ${ }^{7}$

Durante o período em que estabelecemos um cotidiano no campo empírico, consideramos as narrativas dos entrevistados tão reveladoras dos modos de vida que, especificamente neste texto, priorizaremos as abordagens decorrentes desta análise, deixando à parte as considerações quantitativas neste texto. Esta escolha se justifica pelo caráter analisador institucional das narrativas que, na forma de relatos, queixas, murmúrios, silenciamentos e até mesmo recusas, ${ }^{8}$ fizeram emergir os acontecimentos discursivos relacionados aos modos de vida presentes neste campo. Os enunciados que habitam no interior das narrativas anunciam, conforme Foucault (2005) um acontecimento produzindo sentido e que não se esgota nele mesmo.

O enunciado está ligado, de um lado, a um gesto de escrita ou à articulação de uma palavra, mas, por outro lado abre para si mesmo uma existência remanescente no campo de uma memória, ou na materialidade dos manuscritos, dos livros e de qualquer forma de registro; em seguida, porque é único como todo acontecimento, mas está aberto à repetição, à transformação, à reativação; finalmente, porque está ligado não apenas a situações que o provocam, e a conseqüências por ele ocasionadas, mas, ao mesmo tempo, e segundo uma modalidade inteiramente diferente, a enunciados que o precedem e o seguem (Foucault, 2005, p. 32-33).

Neste artigo, nossa análise buscou estabelecer a forma como as narrativas que descrevem um modo de vida neste contexto específico se articulam com os enunciados que demarcam o consumo de psicofármacos como uma tecnologia de si no contemporâneo. As características de uma pesquisa-intervenção, metodologia reconhecida pela sua forma de ação crítica e implicativa, também pode ser definida como uma das condições deste trabalho (principalmente pelo viés político da análise). No entanto, nossa atuação na pesquisa se deteve, até este momento, à análise das condições de emergência do dispositivo da medicalização, sem que produzíssemos transformações sobre as circunstâncias verificadas neste estudo.

\section{Problematizando o Tema}

Quando este estudo foi iniciado, pensávamos que a questão do consumo de psicofármacos pudesse emergir através da produção de sintomas e que estes seriam efeitos dos modos de vida. No entanto, a análise nos mostrou que o dispositivo da medicalização (dentro do qual se insere o consumo de psicofármacos) como um dos dispositivos centrais de uma estratégia de controle próprio à biopolítica. 
De acordo com Foucault (2001), o processo de medicalização iniciou no século XVIII. Historicamente apareceu acoplado a um modelo de saber científico como coadjuvante no tratamento da doença - contribuindo para legitimar o lugar da clínica nosográfica e do esquadrinhamento da doença. Como atualização ${ }^{9}$ do método clínico, por meio da medicalização o paciente se torna objetificado a partir de uma verdade que representa um saber legitimado sobre uma determinada espacialidade corporal, atuando assim como normalização da vida.

Neste contexto, ao pensarmos a medicalização como interior à biopolítica, ela emerge como um dispositivo que age como uma forma de individualização do poder, na medida em que o consumo de psicofármacos (elemento em análise aqui) se constitui em uma tecnologia de si. A biopolítica para Foucault consiste na ação do Estado ao controlar os corpos da mesma forma que controla a população (Foucault, 2002, p. 293). Assim a medicalização também adquire esta dupla faceta, ao controlar os corpos individualmente e ao utilizar as ferramentas de gestão da população (como, por exemplo, programas e políticas de saúde destinados ao controle da natalidade nas camadas pobres da população)

A medicalização como um dispositivo biopolítico emerge na cena moderna com os programas de higienização realizados na Europa entre os séculos XVII e XVIII, onde emerge como medida de saneamento coletivo para banir pestes, infecções e doenças ao tratar a água e o ar - sem dizer da separação de doentes, prostitutas e desocupados que passaram a habitar os arrabaldes das cidades deixando o centro "livre" de contaminação. A medicalização assume uma conformação que se adapta à biopolítica. No sentido de clarear esta afirmação, retomamos a definição de Foucault com relação à biopolítica:

a nova tecnologia que se instala se dirige à multiplicidade dos homens, não na medida em que eles se resumem em corpos, mas na medida em que ela forma, ao contrário, uma massa global, afetada por processos de conjunto que são próprios da vida, que são processos como o nascimento, a morte, a produção, a doença. Logo depois de uma primeira tomada de poder sobre o corpo que se fez consoante ao modo de individualização, temos uma segunda tomada de poder que, por sua vez, não é individualizante, mas que é massificante ... que se faz em direção não do homem-corpo, mas do homem-espécie. Depois da anátomo-política do corpo humano, instaurada no decorrer do século XVIII, vemos aparecer, no fim do mesmo século, algo que já não é uma anátomopolítica do corpo humano, mas que eu chamaria de uma 'biopolítica' da espécie humana (Foucault, 2002, p. 289).

Foi pensando como o dispositivo de medicalização age enquanto uma estratégia de controle dos corpos e da população que nossa análise revelou uma determinada forma de conformação do poder que se apresenta construída sobre um tripé biopolítico produzido pela dependência, assistencialismo e individualismo - características presentificadas nos modos de vida do contexto analisado.

A escuta como exercício cotidiano de intervenção no campo empírico ${ }^{10}$ nos permitiu encontrar evidências (nas narrativas) relacionadas à rede enunciativa que delimita o sentido atribuído pelos sujeitos à noção de saúde. É importante ressaltar que tomamos aqui a noção de intervenção no sentido amplo, uma vez que ao solicitar que alguém fale, nos colocamos em uma posição de implicação e mobilização política a respeito da forma como o pesquisador e o entrevistado se posicionam frente ao mundo, à sociedade e a sua vidas. Pesquisar-intervindo implica em tomar como princípio a idéia que a fala não é um simples "dado" cuja somatória reforça o peso da análise (como é o caso de determinados usos de pesquisas de base quantitativa). Trata-se aqui de pensar os efeitos do que produzimos, tanto ao mobilizar os sujeitos, como ao divulgar o que pudemos compreender a partir da análise que empreendemos. Butler (2007, p. 22), ao pensar o estatuto da narrativa de si a partir de Foucault, afirma que quando falamos (mesmo que as condições do que pode ser dito ultrapassem o sujeito), estamos implicados em um jogo de reconhecimento de nós mesmos que se constrói também a partir de um arranjo particular da norma que nos constitui no interior dos processos de subjetivação. Trata-se, portanto do que somos, mas também do que podemos ser, pois mesmo que a legitimidade do que pode ser dito esteja determinada de antemão, ela não conforma completamente o sujeito. É importante lembrarmos que para Foucault não existe poder sem liberdade, e é por esta razão também que, ao escutarmos e ao produzirmos um determinado saber sobre o que foi dito, nos posicionamos na posição daqueles que podem pensar e fornecer ferramentas para que as pessoas possam se pensar de outra forma, ou seja, que elas possam ser mais livres do que pensam ser (afirmação que tomamos de Foucault sobre o sentido que ele atribui a sua obra).

Enredados no jogo enunciativo que se assenta no tripé biopolítico descrito acima, quando solicitados(as) a falar sobre o sistema de saúde local, os(as) entrevistados(as) descreviam que um bom sistema de saúde se definia como aquele que "beneficia as pessoas" ou ainda "oferece tudo que elas precisam, não deixando faltar nada". No entanto, (curiosamente) nenhuma das narrativas fez referência aos programas de prevenção que existem no município em questão e que são relativamente qualificados. Esta questão mereceria uma análise mais aprofundada da tradição das políticas de saúde no Brasil que separam a prevenção da assistência; entretanto, o que podemos apontar nos limites deste artigo é que esta tradição se atualiza aqui, nos modos como o uso de psicofármacos (assim como o 
uso de medicamentos em geral e das tecnologias ditas "duras") substituem formas mais reflexivas a respeito dos modos de vida, fazendo assim, eco a forma de apresentação do poder que se baseia no assitencialismo, na dependência (do gestor, do profissional da saúde, etc.) e do individualismo. Estes elementos atuam conjuntamente e são potentes formas de controle individual e coletivo. Como resultado, encontramos uma expressão cultural do que se compreende por saúde que escapa ao direito constitucionalmente adquirido, ${ }^{11}$ sendo esta (a saúde) definida na forma de prestação de serviços, construída em torno da idéia de benesse (não de direito social), cuja forma de ação do sistema pode ser definida como uma "proteção assistencialista". O que ressaltamos aqui é o modelo que se constrói de relação com o Estado, o qual não toma a saúde como um direito (enunciado forte tanto pela sua afirmação no plano institucional-legal, como pela sua ausência nos relatos principalmente quando os entrevistados(as) se referem à dispensação de medicamentos pelo sistema público), mas sim como uma benesse que depende do governante, configurando-se, portanto, em uma política de governo e não uma política de Estado.

Contribuiu para legitimar esta forma de pensamento (acerca da gratificação) a forma de implementação de equipamentos no setor da saúde - propiciada pela emancipação de antigos distritos (hoje municípios) e garantida constitucionalmente. No entanto, a maior parte destes novos municípios não possui equipamentos suficientes que correspondam ao nível secundário de um distrito sanitário (serviço hospitalar com procedimentos básicos), tornando estes novos municípios contínuos dependentes dos mesmos serviços dos municípios-sede que utilizavam antes da emancipação. ${ }^{12}$

Esta relação política entre população e governo se tornou um dos analisadores fundamentais deste estudo, apontando a medicalização como um dispositivo que opera num jogo de poder/controle. A rede enunciativa aparece, muitas vezes, marcada pelos domínios repressivos da fala (a dificuldade em falar sobre o serviço de saúde/doença/ práticas de cuidado) e pela vulnerabilidade (aqui presentificada pelo medo de perder algo que é da ordem da benesse e não do direito) relacionada ao recebimento de medicamentos, equipamentos e serviços (o receio de que a fala significasse "queixa" e que disso desencadeassem a perda do serviço). A partir dos relatos nos aproximamos da relação de gratidão em relação aos serviços de saúde, principalmente no que se refere à dispensação de medicamentos ${ }^{13}$ pelo sistema público do município.

A intenção de um sujeito falante, conforme Foucault (2005, p. 31) se situa nas possibilidades de enunciação em um determinado tempo e contexto. O jogo enunciativo se alimenta daquilo que pode ser dito e daquilo que deve ser silenciado. Trata-se do que é possível dizer a partir do que foi construído no jogo de relações saber-poder que marca a legitimidade de uma fala. É o enunciado, no interior do arranjo que o define, que anima a voz que escutamos. Não se trata da análise do inconsciente (como pensado pela psicanálise) que anima a fala do sujeito, mas de arranjos enunciativos de um tempo e de um contexto precisos que vão constituir os elementos próprios a uma cultura específica. Nas pequenas fraturas do dizer, assim como nas suas tão presentes repetições que verificamos a conjugação da ação biopolítica com a conformação das formações discursivas ${ }^{14}$ que compõem no coletivo a compreensão sobre o programa de saúde:

\begin{abstract}
... não tenho do que me queixar. O próprio prefeito quando era técnico de enfermagem e depois secretário da saúde, sempre foi o cuidador desta gente toda, atendia toda esta pobreza, não importasse o dia ou a hora, medindo pressão, levando remédio, ou chamando a ambulância (Agricultor, 57 anos).
\end{abstract}

Fundamentalmente, relatos como este situam a forma da ação biopolítica. Encontramos aqui uma forma cultural própria à administração pública, ou seja, o governo da saúde como uma extensão do governo da população. Como é próprio da governamentalidade (Foucault, 2004b), aquele que bem governa o corpo bem governa a população e está atento às necessidades e fragilidades do povo. Características como estas definem as condições paternalistas na relação dos gestores com a população.

Cabe ressaltar que a inexpressiva participação da população nas políticas públicas ${ }^{15}$ contribui para o efeito de controle da governamentalidade biopolítica, deste modo, as fissuras na ação do dispositivo não são locus de emergência de uma resistência coletiva. Tal constatação emerge das entrelinhas dos relatos e da posição dos sujeitos em relação às políticas - que esperam por algo como se a responsabilidade sobre suas vidas fosse de competência do Estado.

Do mesmo modo, encontramos nos relatos dos(as) usuários(as) da rede local de atenção à saúde uma queixa que não se refere à falta de conhecimento técnico dos prestadores de serviços, do modo de assistência e ainda menos dos equipamentos destinados à saúde. A queixa do usuário se refere à vulnerabilidade ${ }^{16}$ no uso das tecnologias (medicamentos, serviços e equipamentos), pois atribui ao município um encargo de cuidado relacionado à proteção. Isso ocorre porque constrói uma noção de saúde relacionada à garantia de tratamento ao invés da produção de condições de vida.

As narrativas ${ }^{17}$ nos falam também de algumas especificidades do consumo de psicofármacos no interior do dispositivo de medicalização: em razão de um discurso de vitimização produzido pelo sintoma/doença, observamos como efeito, não apenas o consumo de tecnologias, mas a necessidade de dar visibilidade ao sofrimento (produzindo compaixão e penalização). Como podemos verificar nesta fala: 
Ignácio, V.T.G.; Nardi, H.C. “A medicalização como estratégia biopolítica: um estudo sobre o consumo de psicofármacos...

Nossa vida é muito difícil. Eu tenho muitos problemas de saúde e meus filhos não me ajudam. Não trabalho há muito tempo e vivo de aposentadoria que não cobre as despesas. Em compensação, graças à Deus e à prefeitura que sempre ajudou, eu tenho todos os remédios que preciso. O prefeito também mandou construir esta casinha que eu moro, antes era um puxado, agora tem até banheiro. Tanto pedi que consegui, expliquei que sempre fui uma pessoa doente e sem dinheiro a gente não faz nada, mas como que ia trabalhar se era doente?... Mas ainda bem que eles dão tudo e se depender de mim sempre vou votar neles para eles continuarem me ajudando (Aposentada, 71 anos).

Identificamos neste e outros relatos a forma como as instituições se reproduzem e, ao fazê-lo, produzem os modos de vida da população (benesse, gratificação, dependência) - a repetição dos mesmos sintomas em hierarquias distintas da estrutura da sociedade local. Conforme declaração do gestor público municipal no programa de rádio semanal da prefeitura (05/07/2006):

Como todos sabem, o país atravessa um momento de crise financeira muito intensa e isso não se reflete de forma diferente em nosso município. $O$ que acontece é uma extensão da crise. Apesar de nossa arrecadação ser regular, dependemos muito das verbas que vêm de cima [governo federal]. Então a gente pede a colaboração de todos, para que contribuíam, principalmente compreendendo as medidas de contenção financeira que tomamos para não piorar a crise..., meu muito obrigado e com a graça de Deus, estaremos aqui novamente na semana que vem.

Neste pronunciamento público observamos uma articulação argumentada acerca dos programas de contenção de gastos (cortes no orçamento da saúde e outros setores), sendo que em seguida (dois meses depois) assistimos a retomada dos "benefícios" (dispensação irrestrita de medicamentos, deslocamentos para consultas e exames médicos com maior freqüência). Assim, a análise dos relatos, nos permitiu definir que a existência de uma prática biopolítica habitava na sutileza das integrações, distanciamentos e aproximações, de modo que o poder se consolidava na versatilidade que o sustenta. Isso nos faz compartilhar da definição de Deleuze (2005, p. 81) quando diz que "ao mesmo tempo locais, instáveis e difusas, as relações de poder não emanam de um ponto central ou de um foco único de soberania, mas vão a cada instante "de um ponto a outro no interior de um campo de forças, marcando inflexões, retrocessos, retornos, giros, mudanças de direção, resistências... constituem estratégias e escapam as formas estáveis do visível e do enunciável".

Afirmando estas condições de instalação do poder, as instituições (educação, religião, saúde, trabalho) legitimadas neste campo social, se fortalecem num conjunto de saberes e práticas e contribuem para que a medicalização se instale como um dispositivo. Como podemos verificar nesta fala:

O que eu posso dizer... só posso dizer que seria até um pecado reclamar do atendimento na saúde. Depois que sofremos com a falta de estrutura, recebemos a graça deste posto de saúde e não podemos abrir a boca para reclamar. Aprendemos a dar valor aos médicos, obedecer a suas indicações [fazendo exames e tomando os remédios que eles determinam] $e$ pedir a Deus para que isso nunca nos falte (Aposentada, 76 anos).

O dispositivo da medicalização forja um domínio nas tecnologias de si que se afirma também por uma forma de mutismo que demarca sua presença como máquina de fazer calar. Neste sentido, a medicalização instala a tolerância e, enquanto as emoções estiverem controladas, dificilmente serão instaladas formas de resistência coletivas. Por esta razão, tal dispositivo é entendido simultaneamente como princípio inibidor e mantenedor de uma forma específica de poder.

A partir da prática do consumo que se materializou nos corpos podemos anunciar a existência de um itinerário de segregação em que o sujeito que consome não sofre (mas também não goza); estando neutralizado não se preocupa consigo e/ou com os outros e constitui gradativamente modos de vida individualizantes e totalizantes ao mesmo tempo.

Os relatos abaixo são particularmente evidentes e emergiram quando os(as) entrevistados(as) eram questionados(as) sobre como pensavam a produção do sintoma e por conseqüência o consumo:

Eu não sei ao certo se isso é depressão porque já vi pessoas piores do eu me sinto, mas tem uma tristeza que veio vindo, veio vindo e nunca mais se foi. Tem também o fato de que aqui em Boa Vista a gente vive muito isolado de tudo, das pessoas. Tem o trabalho, a igreja e só. Cada um vive sua vida, cuida do seu trabalho, do seu patrimônio e pronto. Eu também vivo assim, mas gostaria que fosse diferente, gostaria de conviver mais com as pessoas, saber o que acontece do lado de fora da minha casa, entende? Os remédios para dormir me ajudam bastante a enfrentar isso, e a gente ganha, para isso temos assistência, não posso reclamar (Agricultora, 39 anos).

Acho que um dos fatores que leva as pessoas a tomarem estes remédios é o fato de que não existe nada para fazer [lazer] além de assistir televisão, ir na pracinha ou numa festa que tem de vez em quando. Na maioria das vezes a gente fica em casa. Eu não tenho problemas de depressão ou insônia, mas as vezes fico meio assim, não sei dizer o que é. Me sinto muitas vezes sem vontade para nada, a gente não tem estímulo de convivência, e de alguma forma, já se acostumou a não ter nada para fazer, por isso 
todo mundo aqui é meio assim, fica mais por casa, entendeu? (Estudante, 19 anos).

Falas como estas contextualizam, segundo os próprios moradores, a produção de sintomas comuns à melancolia e o embotamento. Com isso, podemos verificar o que aparece associado como resultantes e/ou resul-tados do enclausuramento que desencadeia modos individualistas. Por esta razão, mesmo que as pessoas não consumam psicofármacos elas funcionam de uma forma muito próxima àqueles que consomem, produzindo narra-tivas semelhantes, pois afinal, estão inscritas num mesmo território de pertencimento.

Situamos no interior desta fala interconexões produtoras de sentido que, se não determinam, contribuem para que o uso dos psicofármacos enquanto uma tecnologia legitimada pelas instituições, adquira cada vez mais o estatuto de normalidade. A fala revela vicissitudes que definem modos individualistas, no entanto, devemos considerar as características culturais e geográficas deste pequeno município: há um esquadrinhamento do indivíduo pela segregação dos lares ${ }^{18}$ - naturalizando uma anestesia social.

\section{O Lugar do Profissional em Saúde}

Como dissemos anteriormente, o lugar ocupado pelo sujeito ao falar no interior da rede enunciativa analisada associa a utilização do medicamento como prática central no tratamento de saúde como qualidade em saúde um ideal que parte da prescrição e dispensação de medicamentos.

O consumo de medicamentos como tecnologia de si aparece tão imperativa que o médico não é o ator principal do ato de prescrição - ele se encontra aprisionado numa engrenagem biopolítica de gestão em saúde, onde ações transformadoras desta tecnologia não procedem, pois não mais escapam à medicalização.

Tratamos assim das especificidades de um contexto social definido hierarquicamente por posições de saber, conhecimento e poder. Podemos analisar mais claramente estes jogos de poder na fala de um médico do sistema público local:

eu já comprei muita briga trabalhando aqui por conta deste problema da medicalização, já disse que não adianta 'entupir a farmácia' de remédio e não criar programas eficazes para uma conscientização. Mas a coisa parece vício e não muda. Por exemplo, temos muitos alcoolistas, aí tem os medicamentos, e isso ajuda até certo ponto, mas precisava ter grupos de apoio ao dependente e à família. Isso seria mais efetivo, garantiria mais estabilidade, é diferente do que fazemos que é solução circunstancial e não contínua. Mas vai convencer os gestores disto... Só nos resta trabalhar com o que temos.

Nesta colocação fica evidente a existência de uma posição/produção crítica acerca da problemática - do mesmo modo que é evidente o aprisionamento dos profissionais ao sistema, o que circunstancialmente os torna mantenedores de tal problemática.

Em algumas narrativas, podemos situar as fissuras que definem a governamentalidade biopolítica - a exemplo de como os sujeitos descrevem suas expectativas em relação ao sistema de saúde e seus profissionais:

... eles às vezes são meios estranhos. A assistente
social quer colocar minha mãe no asilo. Só que daí
eu não recebo o beneficio da aposentadoria, o di-
nheiro vai direto para o asilo. O neurologista não
quis dar o laudo do meu filho para encostar ele como
inválido, claro que ele tem problema na cabeça, faz
dez anos que tá na segunda série... não é muito que
daria pra fazer com esta aposentadoria, mas já ajuda
com os remédios. O que a gente recebe sempre [do
posto] são os remédios para a cabeça, disso não
posso reclamar, nunca faltou o gardenal. Agora to
vivendo com os 80 reais do bolsa família, é 40 reais
por filho. Tem dias que trabalho tem dias que não,
as patroas não são fáceis. Ainda bem que recebo da
bolsa senão ia ficar difícil.

Na mesma entrevista, sua opinião sobre o atendimento médico:

"Olha, tem uns que ajudam a gente, mas outros não tão nem ai, ficam se negando a dar laudo, receita, pensam que a gente não sofre. Queria ver eles vivendo com 80 reais..."

A análise dos enunciados que delimitam as falas nos permite encontrar o lugar onde as expressões do poder nascem e se reproduzem, encontrando condições para se instalar e se intensificar. Também nestes espaços, encontramos muitos momentos de silenciamento e recusa em emitir uma opinião sobre como percebiam o sistema de saúde local. Nos lugares onde a biopolítica atua, define e reproduz de forma mais coercitiva os modos de vida, se tornaram mais visíveis os domínios do silenciamento. A interdição da linguagem como um elemento interior ao dispositivo da medicalização contribuiu para a normalização desta tecnologia e para o exercício do biopoder - o controle dos corpos através da medicalização.

\section{Apontamentos Conclusivos}

Inicialmente nosso estudo buscou compreender os modos como o sujeito é capturado pelo dispositivo da medicalização. Consequentemente isso nos apontou para as especificidades da ação do dispositivo no contexto em que o sujeito é(auto)constituído, tomando como analisador o consumo de psicofármacos (enquanto componente do dispositivo de medicalização) em Boa Vista das Missões.

$\mathrm{Na}$ (con)vivência de campo de seis meses, compreendemos a partir de um cotidiano como foi construída no tempo e nos modos políticos específicos deste contexto 
(também formas de associação local-global que marcam as formas de governo da vida contemporânea) a legitimidade dos modos de cuidado nos quais o medicamento tem lugar central. Trata-se de uma tecnologia que promete o afastamento do sofrimento de diversas origens (depressão, ansiedade, transtornos psicóticos, solidão, crises econômicas, tristeza) em detrimento de outras formas de resistência aos modos de captura subjetiva ali presentes. A formatação individualista associada a um modo de governar assistencialista e paternalista diminui as possibilidades da emergência de formas coletivas de enfrentamento do sofrimento. Nos restringimos neste primeiro momento a uma intervenção pela escuta na produção deste ciclo de silenciamentos, ansiedades e angústias.

Se a perspectiva inicial deste estudo esteve centrada no "consumo" como maior atravessador analítico, a experimentação no campo nos fez perceber que este foi um dos analisadores de um contexto sócio-político pleno de variáveis. O desdobramento de alguns (des)caminhos onde se situavam os acontecimentos nos permitiu escutar os agenciamentos que legitimaram o consumo de psicofármacos no interior do dispositivo da medicalização (a dependência, o assistencialismo e o individualismo).

As narrativas foram cuidadosamente analisadas na tentativa de visibilisar os enunciados que dão sentido a uma determinada forma de existir no mundo neste contexto e que habitam o interior desta cultura. Ao preterirmos uma explicação centrada na análise exclusivamente estatística para as razões que elevaram o consumo de psicofármacos nesta cidade (como poderíamos ter feito se nos restringíssemos à análise das variáveis), adentramos no espaço constitutivo da gestão política de saúde. Esta forma de gerir e produzir saúde em uma lógica mercadológica, pois compra-se saúde ao consumir medicamentos e consultas (seja este consumo patrocinado pelo Estado ou pelo próprio bolso) legitimando uma dupla dependência. Um destes modos de dependência é mais social (atribuída ao gestor) e outra mais individualizada (centrada no corpo, na solução química para todos os males). Acoplando assim, como bem nos ensina Foucault, formas de controle próprias ao biopoder, pois são totalizantes e individualizantes ao mesmo tempo.

Na condição de uma das principais tecnologias contemporâneas de cuidado, o consumo de psicofármacos aparece associado à instalação de uma eficaz química no organismo (antidepressivos e ansiolíticos principalmente) e emerge como um veículo de acesso à saúde. De acordo com Lefèvre (1992) há uma correspondência que o sujeito estabelece ao consumir medicamentos: é uma forma de produzir equivalências às noções atribuídas à saúde e gerar pertencimentos de normalização legitimados socialmente.

A análise da ação do dispositivo da medicalização está relacionada às forças/formas vigentes da produção de subjetividade no contemporâneo e fez emergir, na pers- pectiva deste estudo, um elenco de problematizações associadas. Desta forma, podemos dizer que o dispositivo da medicalização se justifica e se reproduz, em maior ou menor grau, ao legitimar o consumo de medicamentos psicoativos como uma forma de cuidado ao construir formas de vida fundamentadas no individualismo/isolamento e ao legitimar modos de governo de caráter assistencialista/paternalista nos quais predominam os modos populistas de gestão e amarras institucionais repressivas e/ou controladoras que, conjuntamente, fazem com que não haja um deslocamento nas formas de dependência.

Podemos dizer também que o silenciamento como forma de controle biopolítico desconecta as pessoas e inibe as formas coletivas de resistir enquanto que a medicalização se apresenta como uma forma de (não) enfrentamento, sem que outras possibilidades estejam investidas efetivamente na vida dos sujeitos. O consumo de psicofármacos é, portanto, uma tecnologia de si que se encontra intensificada e naturalizada nos corpos, a qual passou a definir as condições de saúde de uma sociedade ao silenciar os corpos. Esta tecnologia se consolidou como o sentido atribuído à saúde neste meio e, enquanto estes modos de vida sobreviverem, sempre haverá fluoxetinas, sertralinas, diazepams, alprazolams...

\section{Notas}

1 De acordo com a perspectiva foucaultiana investigação questiona quando e como surgiram as condições para que uma situação se instalasse tal como a encontramos. Compreende o uso de ferramentas não convencionais para entender as transformações tais como: traços, memórias, registros falados ou escritos, ditos e não-ditos. Tal perspectiva nos permite verificar em que condições se estabelece a emergência do sujeito/objeto que investigamos.

2 As tecnologias de si contemporâneas fazem parte dos modos que o sujeito contemporâneo encontra na cultura (no caso em análise, interiores ao dispositivo da medicalização) e que são sugeridos, propostos ou impostos pela sociedade ou grupo social. (Nardi \& Silva, 2005, p. 94). A análise destas técnicas de si no contemporâneo nos aproxima dos modos de organização e das especificidades de uma sociedade - na forma que as instituições são constituídas e o poder é legitimado. Segundo Foucault (2004a) são o conjunto de tecnologias e experiências que participam do processo de (auto)constituição e transformação do sujeito. Dados: Conselho de Desenvolvimento do Médio Alto Uruguai (CODEMAU) de 2005.

4 CODEMAU (2005).

5 Boa Vista das Missões era distrito de Palmeira das Missões (RS) antes de obter emancipação política.

6 A distinção do levantamento atual em relação ao anterior (2004) pode ser definida pela especificidade do questionário, antes aplicado por Agentes Comunitárias (que atuam in loco de intervenção, direcionando a coleta aos prováveis usuários que participam do programa de saúde do PACs); enquanto que os resultados desta pesquisa (2006) foram decorrentes de uma busca dos entrevistados na população total a partir da estratificação proposta pelo Instituto Brasileiro de Geografia e Estatística (IBGE). O projeto de pesquisa foi aprovado pelo comitê de ética da Universidade Federal do Rio Grande do Sul e os(as) entrevistados 
assinaram o termo de consentimento informado, no qual estava garantida a confidencialidade. Ainda com relação aos aspectos éticos da pesquisa, o projeto foi apresentado aos responsáveis municipais pela área da saúde, contando com a concordância institucional. O retorno dos resultados aos participantes foi garantido a partir da disponibilidade do contato com os pesquisadores de forma individual e, de forma coletiva, a partir do interesse institucional. O contato com o município permanece aberto para futuros desdobramentos da pesquisa, além disso buscaremos a divulgação dos resultados por meio de um relatório simplificado de nossas conclusões centrais que poderá ser acessado pela população e pelos profissionais da saúde.

8 Para Baremblitt (1996) analisadores podem ser entendidos como situações de recusa, receio e "murmúrios" e fazem parte de uma composição social. O analisador espontâneo é um fenômeno emergente que se encontra presente no campo de análise e surge como resultado de forças contraditórias que se articulam e aparecem na forma deste fenômeno e se refere às instituições envolvidas.

9 A legitimidade de uma consulta clínica é afirmada mediante a prescrição medicamentosa.

10 O período de intervenção no campo empírico (Boa Vista das Missões) teve duração de seis meses e se caracterizou pelo estabelecimento de um cotidiano de entrevistas e visitas/observações nos espaços de circulação.

11 Artigos 196-200 da Constituição da República Federativa do Brasil (1988/2000).

12 Os dados sobre os equipamentos de saúde dos pequenos municípios podem ser verificados no site do IBGE (2006).

13 Na pesquisa relacionada ao estudo em questão verificamos especificamente os medicamentos psicoativos (antidepressivos, ansiolíticos e antipsicóticos)

14 Segundo Foucault (2005, p. 43) as formações discursivas podem ser definidas como uma regularidade (uma ordem, correlações, posições e funcionamentos) dos enunciados e seu arranjo interdependente.

15 Uma leitura mais ampla sobre a participação popular nos processos democráticos do município pode ser verificada em Ignácio (2006).

16 Conforme Castel (1998) a vulnerabilidade pode ser entendida como aquela zona de alimento às turbulências que fragilizam as situações conquistadas e desfazem os estatutos assegurados. A permanência na zona de vulnerabilidade social, afetiva, política e econômica é também o que torna o dispositivo da medicalização um modo de subjetivação no contexto em que desenvolvemos este estudo.

17 Para Foucault (1977, p. 12) “as práticas discursivas não são pura e simplesmente modos de fabricação de discurso. Ganham corpo em conjuntos técnicos, em instituições, em esquemas de comportamento, em tipos de transmissão e de difusão, em formas pedagógicas que ao mesmo tempo as impõe e as mantém".

18 Foi neste cenário que observamos uma situação característica: as casas estão sempre fechadas e, independente do horário as ruas permanecem vazias - onde as pessoas circulam apenas em decorrência de alguma necessidade.

\section{Referências}

Baremblitt, G. F. (1996). Compêndio de análise institucional e outras correntes: Teoria e prática. Rio de Janeiro, RJ: Rosa dos Tempos.

Butler, J. (2007). Le récit de soi. Paris: PUF.

Castel, R. (1998). As metamorfoses da questão social: Uma crônica do salário. Petrópolis, RJ: Vozes.
Conselho de Desenvolvimento do Médio Alto Uruguai. (2005). Boa Vista das Missões. Frederico Westphalen, RS: Autor.

Constituição da República Federativa do Brasil (2000). Texto constitucional de 5 de outubro de 1988 com as alterações adotadas pelas Emendas Constitucionais de n.1 de 1992, a 28 de 2000 e pelas Emendas Constitucionais de Revisão de $n .1$ a 6, de 1994 (14. ed.). Brasília, DF: Câmara dos Deputados, Coordenação de Publicações. (Original publicado em 1988)

Deleuze, G. (2005). Foucault (5. ed.). São Paulo, SP: Brasiliense.

Foucault, M. (1977). História da sexualidade I: A vontade de saber. Rio de Janeiro, RJ: Graal.

Foucault, M. (2001). O nascimento da clínica (5. ed.). Rio de Janeiro, RJ: Forense Universitária.

Foucault, M. (2002). Em defesa da sociedade: Curso no Collège de France (1975-1976). São Paulo, SP: Martins Fontes.

Foucault, M. (2004a). A hermenêutica do sujeito. São Paulo, SP: Martins Fontes.

Foucault, M. (2004b). A “governamentalidade". In Ditos e escritos IV (pp. 281-305). Rio de Janeiro, RJ: Forense Universitária.

Foucault, M. (2005). A arqueologia do saber (7. ed.). Rio de Janeiro, RJ: Forense Universitária.

Ignácio, P. R. G. (2006). Processos democráticos num pequeno município do interior gaúcho: O caso de Boa Vista das Missões. Dissertação de Mestrado em desenvolvimento, Universidade de Ijuí, RS.

Instituto Brasileiro de Geografia e Estatística. (2006). Cidades@: Boa Vista das Missões. Brasília, DF: Autor. Retirado em nov. 2006, de http://www.ibge.com.br

Lefèvre, F. (1992, dez.). Remédio: Saúde ou indústria? A produção de medicamentos no Brasil. Cadernos de Saúde Pública, 8(4), 470-470.

Nardi, H. C., \& Silva, R. N. da. (2005). Ética e subjetivação: As técnicas de si e os jogos de verdade contemporâneos. In N. Guareschi \& S. Hüning (Eds.), Foucault e a Psicologia. Porto Alegre, RS: Abrapso Sul.

Vivian Tatiana Galvão Ignácio é mestre em Psicologia Social e Institucional pela Universidade Federal do Rio Grande do Sul, Bolsista do CNPq e docente na UMESC-RO. galvaovivian@gmail.com

Henrique Caetano Nardi é doutor em Sociologia e docente no programa de Pós-Graduação em Psicologia Social e Institucional da Universidade Federal do Rio Grande do Sul hcnardi@terra.com.br

A medicalização como estratégia biopolítica: um estudo sobre o consumo de psicofármacos no contexto de um pequeno município do Rio

\section{Grande do Sul}

Vivian Tatiana Galvão Ignácio \& Henrique Caetano Nardi Recebido: 3/4/2007

$1^{a}$ revisão: 28/8/2007

Aceite final: 30/8/2007 